\title{
Long-term Effects of Unilateral and Bilateral Otitis Media and Myringotomy on Long-Latency Verbal and Non-Verbal Auditory-Evoked Potentials
}

\author{
Milaine Dominici Sanfins ${ }^{1}{ }^{10}$ Caroline Donadon $^{1}$ Letícia Reis Borges ${ }^{1}$ Piotr H. Skarzynski ${ }^{2,3,4}$ \\ Maria Francisca Colella-Santos ${ }^{1}$
}

${ }^{1}$ Human Development Department, Faculdade de Ciências Médicas, Universidade Estadual de Campinas, Campinas, Brazil

2 Department of Teleaudiology and Hearing Screening, World Hearing Center, Institute of Physiology and Pathology of Hearing, Warsaw/ Kajetany, Poland

${ }^{3}$ Department of Heart Failure and Cardiac Rehabilitation, Warsaw, Poland

${ }^{4}$ Department of Science and Development, Institute of Sensory

Organs, Warsaw, Poland

Int Arch Otorhinolaryngol 2020;24(4):e413-e422.

\author{
Address for correspondence Milaine Dominici Sanfins, MDS, \\ Departamento de Desenvolvimento Humano, Faculdade de Ciências \\ Médicas, Universidade Estadual de Campinas, Campinas, Avenida \\ Jacutinga, 220 - apto 12, Indianópolis, São Paulo, 04515-030, SP, Brazil \\ (e-mail: msanfins@uol.com.br).
}

\begin{abstract}
Keywords

- hearing

- otitis media

- electrophysiology

- long-latency auditory-evoked potential

- children

Introduction Otitis media (OM) is considered one of the most common reasons patients seek medical care in childhood. The fluctuating nature of hearing loss in cases of OM leads to irregular sound stimulation of the central auditory nervous system. Objectives To analyze the long-latency auditory-evoked potential (LLAEP) by verbal and nonverbal sounds in children with a history of OM in the first six years of life.

Methods A total of 106 schoolchildren participated in the study, 55 females and 51 males, aged between 8 and 16 years, who were divided into 3 groups: the control group (CG), the bilateral experimental group (BEG), and the unilateral experimental group (UEG). All children underwent a complete audiological evaluation (audiometry, logoaudiometry and immitance testing) and an electrophysiological evaluation (LLAEP with toneburst stimulus - LLAEP-TB, and LLAEP with speech stimulus - LLAEP-S).

Results Both study groups (BEG and UEG) presented a statistically lower performance $(p<0.005)$ when compared with the CG regarding all of the electrophysiological tests with the prolongation of the latency values and decrease in the amplitude values: LLAEP-TB (BEG: latency - N1, P2, N2 [females] and P300, amplitude - N1 and P2), LLAEP-S (BEG: latency - P2 and N2 [females], amplitude - P2 /UEG: latency - P2 and P300, amplitude: N1 and P2). Conclusion Children who had suffered secretory OM in the first six years of life and who had undergone myringotomy for the placement of a ventilation tube, either unilaterally or bilaterally, presented worse performance in their electrophysiological responses to verbal and nonverbal LLAEPs.
\end{abstract}

\section{Introduction}

For the development of speech and language, a sound and active listening system is of fundamental importance. The central auditory nervous system (CANS) can be harmed by several occurrences, including otitis media (OM), which originates from an inflammation in the middle ear and is often associated with accumulation of fluid, either infected or uninfected. Otitis media has a multifactorial pathology, including factors such as infection of the nasal cavities, the received

February 14, 2019

accepted

July 8, 2019
DOI https://doi.org/

10.1055/s-0039-1697006. ISSN 1809-9777.
Copyright $(2020$ by Thieme Revinter

Publicações Ltda, Rio de Janeiro, Brazil
License terms

()(1) $\Theta \circledast$ 
sinus cavities, or the rhinopharynx, which are propagated to the middle ear through the Eustachian tube. ${ }^{1}$

Otitis media is considered one of the most common reasons patients seek medical care in childhood. ${ }^{2}$ Approximately 50\% of 1-year-olds have had at least one OM episode, and at least 2/ 3 of all children have had an episode of OM with effusion(OME) in the first 5 years of life, an affliction that can result in conductive hearing loss of up to $40 \mathrm{~dB}^{3,4}$ Most hearing loss from $\mathrm{OM}$ is conductive and temporary. The fluctuating nature of hearing loss in cases of OM leads to irregular sound stimulation of the CANS, and this can distort sound perception.

Due to contralateral ear involvement, the majority of OM occurrences are bilateral. Although unilateral OM suggests there might be a better overall hearing performance, this is questionable because of CANS effects: it appears that the hearing gap between the ears, either in the unilateral or bilateral asymmetric conditions, leads to a more effective participation of the less compromised ear in capturing sound information. As a result, the performance of the altered ear gradually declines, impairing auditory activities that require binaural hearing. ${ }^{5}$

Knowing that OM causes deleterious effects to the individual, it is important that the treatment be very well established. In short-term cases, one can try a conservative approach, such as insufflation of the Eustachian tube together with decongestant medication. However, in cases of recurrent or long-term $\mathrm{OM}$, this type of treatment is generally not effective. ${ }^{6,7}$ Thus, myringotomy with the placement of a ventilation tube (MVT) appears to be a good alternative, ${ }^{8}$ since it provides an alternative way of aerating the middle ear.

The relationship between OM and adverse effects on oral language development and learning has been well documented. ${ }^{9-11}$ Children with OM hear verbal and non-verbal sounds in a reduced or distorted way, which leads to a loss of auditory cues such as speech formants. These difficulties may remain throughout the school years and adult life, and are especially acute in difficult listening environments. Therefore, an evaluation of the possible effectiveness of myringotomy, combined with a study of how auditory information is processed by the CANS, is recommended. In this context, auditory-evoked potentials (AEPs) are an extremely useful tool to study auditory perception and its abnormalities. ${ }^{12}$

Long-latency AEPs (LLAEPs) are thought to represent a range of cognitive processes that includes the update of the working memory and the transfer of information to consciousness. ${ }^{13,14}$ Long-latency AEPs enable the observation of the neurophysiological substrate of processes that occur in the cortex related to cognition - such as memory, attention, the sequential processing of auditory information, decision making, and auditory discrimination. Eliciting LLAEPs with verbal stimuli provides additional information about the biological processes involved in speech processing, especially since it can provide information that is complementary to that obtained by standard behavioral evaluations (cognitive, auditory, or linguistic). ${ }^{15,16}$ There have been few studies that have aimed at identifying impairment in central auditory function due to OM in children. The aim of the present study was to analyze LLAEP responses evoked by verbal and nonverbal sounds in children with a history of OM in the first six years of life.

\section{Materials and Methods}

\section{Statement of Ethics}

The present study was approved by the Ethics in Research Committee under protocol number 889074. Data were collected between October 2013 and January 2016 at UNICAMP. Informed consent for the research was obtained from all participants after an explanation of the nature, purpose, and expected results of the study.

\section{Participants}

A total of 106 schoolchildren participated in the study, 55 females and 51 males, aged between 8 and 16 years, who were enrolled in a public elementaryschool. The subjects were divided into three groups:

(i) The control group (CG) consisted of 40 students (25 females and 15 males) who had no history of OM and no school complaints.

(ii) The bilateral experimental group (BEG) consisted of 50 students (22 females and 28 males) with a documented history of 3 episodes of OM, and who had been submitted to surgery for insertion of bilateral ventilation tubes in the first 6 years of life. They had normal hearing at the time of the evaluation.

(iii) The unilateral experimental group (UEG) was comprised of 16 students ( 8 females and 8 males) with a documented history of $3 \mathrm{OM}$ episodes, and who had undergone surgery for insertion of unilateral ventilation tubes in the first 6 years of life. They had normal hearing at the time of the evaluation.

All of the children in the study groups (BEG and UEG) who had a documented history of 3 episodes of OME were diagnosed by otorhinolaryngologists. The medical report showed that all patients (before the auditory surgery) had mild to moderate conductive hearing loss and a type-B tympanometry curve associated with the absence of ipsilateral and contralateral acoustic reflexes. According to the 2nd Clinical Practice Guideline, ${ }^{17}$ auditory thresholds can be affected in cases of OME by up to $55 \mathrm{~dB}$ (moderate hearing loss) ${ }^{18,19}$ The average hearing loss associated with OME in children is $28 \mathrm{~dB} \mathrm{HL}$; however, hearing loss in children can exceed $35 \mathrm{~dB} .{ }^{19,20}$

\section{Inclusion Criteria}

The inclusion criteria were defined as:

(i) CG:

- air conduction threshold below $20 \mathrm{~dB}$ HL for octaves from 250 to $8,000 \mathrm{~Hz}$;

- bone conduction thresholds below $15 \mathrm{~dB}$ HL for octaves between 500 to $4,000 \mathrm{~Hz}$;

- type-A tympanogram with compliance between 0.3 and 1.3 mmhos and pressure between -100 daPa and +200 daPa associated with the presence of ipsilateral and contralateral acoustic reflexes in both ears; ${ }^{18,19}$ 
- no current or prior neurological, cognitive, or psychiatric disorders;

- no complaint of learning or speech disorder; and

- no syndromic hearing impairment, or other middle or inner ear diseases.

(ii) BEG and UEG:

- air conduction threshold below $20 \mathrm{~dB}$ HL for octaves from 250 to $8,000 \mathrm{~Hz}$;

- bone conduction thresholds below $15 \mathrm{~dB}$ HL for octaves between 500 to $4,000 \mathrm{~Hz}$;

- type-A tympanogram with compliance between 0.3 and 1.3 mmhos and pressure between -100 daPa and +200 daPa; and

- absence of middle ear infection for a period of 12 months before the date of the evaluation.

In addition to the aforementioned criteria, BEG students needed to submit:

- documented history of three episodes of OME in the first six years of life and bilateral myringotomy with one-time ventilation tube insertion.

In addition to the aforementioned criteria, UEG students needed to submit:

- documented history of three episodes of OME in the first six years of life and unilateral myringotomy with onceonly ventilation tube insertion.

\section{Procedures}

\section{Audiological Evaluation}

a) An audiometric evaluation was performed to assess the air conduction threshold at 250, 500, 1,000, 2,000, 3,000, $4,000,6,000$, and $8,000 \mathrm{~Hz}$, and the bone conduction threshold at $500,1,000,2,000$, and $4,000 \mathrm{~Hz}$. The auditory threshold was considered to be normal up to $15 \mathrm{~dB}$ for air conduction and up to 20 dBNA for bone conduction according to the classification of Davis and Silverman. ${ }^{20}$ The evaluation was performed with an AC 40 audiometer (Interacoustics, Middlefart, Denmark). TDH 39 headsets (Telephonics, Farmingdale, NY, US) were used and calibrated according to the ISO-389 and IEC-645 standards.

b.1) Speech recognition threshold: a list of disyllables was adopted, and the result was the intensity at which the participant correctly scored $50 \%$ of the words presented. b.2) Speech recognition index: the test was performed $40 \mathrm{~dB}$ above the tonal threshold of the mean of $500,1,000$, and $2,000 \mathrm{~Hz}$ using a list of monosyllabic words. It was considered normal if the percentage of correct answers was between $88 \%$ and $100 \%$.

c) Immittance audiometry (tympanometry and acoustic reflex): tympanometry was performed with a $226 \mathrm{~Hz}$ tone. Ipsilateral and contralateral acoustic reflexes were sought at frequencies of 500,1,000,2,000, and 4,000 Hz. The subjects presented a maximum compliance of around 0 daPa and an equivalent volume of 0.3 to $1.3 \mathrm{ml}$ according to the proposal of Jerger (1970). ${ }^{21}$
The immittance audiometry was performed using an Interacoustics AT 235h audiometer. All of the equipment was calibrated according to the ISO-389 and IEC-645 standards. The subjects who presented normal values in the basic audiological evaluation were then tested electrophysiologically.

\section{Long-latency Auditory-Evoked Potentials (LLAEPs)}

The electrophysiological evaluation was conducted using the Biologic Navigator Pro (Natus, Pleasanton, CA, US) device in an acoustically prepared and electrically shielded room. The subjects were comfortably seated in a reclining chair. Before placing the electrodes, the subject's skin was cleaned with an abrasive paste. The electrodes were fixated with an electrolytic paste, and sticky tape was used to ensure a low impedance contact. The skin-electrode impedance was kept below $3 \mathrm{k} \Omega$, and the inter-electrode impedance was kept below $2 \mathrm{k} \Omega$.

During the testing, the subjects were instructed to keep their eyes closed to avoid artifacts. If necessary, changes were made to the subject's position to ensure stable collection conditions. In $50 \%$ of the patients, the testing was first performed in the right ear, and in the other $50 \%$, in the left ear. The LLAEPs were recorded monoaurally under two conditions: right-ear evaluation and left-ear evaluation, and in two steps:

(i) LLAEP with a non-verbal stimulus (toneburst);

(ii) LLAEP with a verbal stimulus (speech).

In recording all LLAEPs, the surface electrodes were positioned according to the 10-20 system, that is, the active electrode was positioned at the apex $(\mathrm{Cz})$, the reference electrode, at M2, the left electrode, at M1, and the ground electrode, at $\mathrm{Fz}^{22}$ The parameters used are shown in - Table 1.

The toneburst stimulus was presented at a frequency of $1,000 \mathrm{~Hz}$ (frequent stimulus) or $2,000 \mathrm{~Hz}$ (infrequent/rare stimulus) in a randomized way, using an oddball paradigm with a total of 300 stimuli, $80 \%$ of which were frequent stimuli $(1,000 \mathrm{~Hz})$ and $20 \%$, infrequent $(2,000 \mathrm{~Hz})$. Runs in which artifacts were greater than $10 \%$ were repeated to obtain reliable responses with fewer artifacts. The children were instructed to remain with their eyes closed during the procedure and mentally count the number of infrequent stimuli and count out loud the number of rare stimuli. Thus, the examiner was able to ensure that the patients performed the task correctly by asking them at the end of the evaluation how many rare stimuli were heard.

\section{Data analysis}

All analyses were performed offline, and the waves were identified visually and marked manually by two audiologists who were blinded to each participant's age, gender, and group (CG, BEG, or UEG). For the analysis, 4 waves were identified visually and marked manually by the evaluator: $\mathrm{N} 1, \mathrm{P} 2, \mathrm{~N} 2$, and P300. The N1, P2, and N2 components corresponding to the frequent stimulus were identified in the tracing, while in the plot corresponding to the rare stimulus the P300 component was identified (-Fig. 1); the latency and amplitude of all components were recorded. 
Table 1 Acquisition parameters for LLAEPs using non-verbal and verbal stimuli

\begin{tabular}{|l|l|l|}
\hline Parameter & Non-Verbal & Verbal \\
\hline Equipment & Biologic Navigator Pro & Biologic Navigator Pro \\
\hline Stimulated Ear & Right ear/Left ear & Right ear/Left ear \\
\hline Type of stimulus & Toneburst & Speech \\
\hline Frequent stimulation & $1,000 \mathrm{~Hz}(80 \%)$ & Syllable /ba/ (80\%) \\
\hline Infrequent stimulus & $2,000 \mathrm{~Hz}(20 \%)$ & Syllable $/ \mathrm{da} /(20 \%)$ \\
\hline Polarity of the stimulus & Alternate & Alternate \\
\hline Intensity of the stimulus & $75 \mathrm{~dB} \mathrm{NA}$ & $75 \mathrm{~dB} \mathrm{NA}$ \\
\hline Speed of the stimulus & $1.1 / \mathrm{sec}$ & $1.1 / \mathrm{sec}$ \\
\hline Number of scans & 300 & 300 \\
\hline Filter & $1-30 \mathrm{~Hz}$ & $1-30 \mathrm{~Hz}$ \\
\hline Window & $533 \mathrm{milliseconds}$ & 533 milliseconds \\
\hline Transducer & Insert (ER-3A; Natus Medical) & Insert (ER-3A; Natus Medical) \\
\hline
\end{tabular}

\section{Statistical Analysis}

The statistical analysis was performed by means of a threeway analysis of variance (ANOVA). The experiment had three categorical effects, in which the main effects were the ear, the sex, and the group, and the interactions of two and three of these effects were considered. To find statistical differences between the groups, pairs of groups were compared using the $t$-test, and the $p$-values were adjusted for multiple comparisons using the false discovery rate (FDR) approach. To test the homogeneity of the sample, the Pearson chisquared test was applied. The level of significance was set at $5 \%(p \leq 0.05)$. The statistical analyses were performed using the R-project ( $\mathrm{R}$ Foundation for Statistical Computing, Vienna, Austria) software.

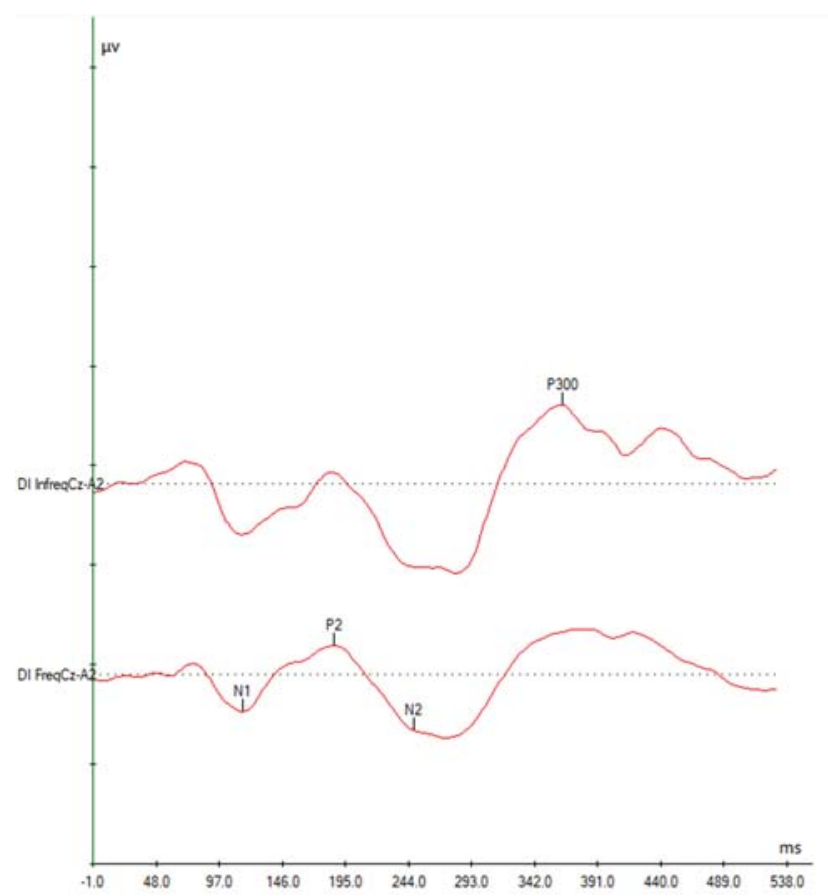

Fig. 1 Identification of LLAEP components.

\section{Results}

\section{Characterization of the Sample}

The sample consisted of 106 students divided into 3 groups that were homogeneous in terms of age ( $8-11$ years old and 12-16 years old; CG: $p=0.15$; BEG: $p=0.88$; UEG: $p=0.80$ ) and sex (male and female; CG: $p=0.13$; BEG: $p=0.18$; UEG: $p=1.00$ ). Thus, the data obtained for each age group and for each sex was combined in the following analysis.

\section{Air and Bone Conduction Audiometric Thresholds}

There were no significant differences among the groups for the audiometric frequencies tested via air and bone. - Table 2 shows that there is no difference greater than 5 dBNA between the means of the thresholds from 250 to $8,000 \mathrm{~Hz}$ (air conduction) or between the means of the thresholds from 500 to $4,000 \mathrm{~Hz}$ (bone conduction).

\section{LLAEP with Non-Verbal Stimulus (Toneburst)}

In terms of latency, there was a difference between males and females in the N2 wave latencies; therefore, these values were analyzed separately using the $t$-test, and the $p$-values were adjusted for multiple comparisons using the FDR approach (-Tables 3 and $\mathbf{4}$ ). - Table 5 shows that the P2 and N2 wave latency differed among females in the CG and BEG. Regarding amplitude, there was a difference between males and females in the amplitude of the P2 wave; therefore, these values were analyzed separately ( - Tables 3 and 4). - Table 5 also shows that, for each of the study groups, there was no significant difference in the amplitude values of the P2 wave for females.

\section{LLAEP with Verbal Stimuli (Speech)}

In terms of latency, there was a difference between males and females in the N2 values, and they were analyzed separately (-Table $\mathbf{6}$ ). - Table 7 shows that there was a significant difference in the latency for N1, P2, N2 (female), and P300. In addition, it can be observed that there was a significant difference in amplitude for N1 and P2. 
Table 2 Comparison among the study groups in terms of average tonal air thresholds in the right and left ears

\begin{tabular}{|c|c|c|c|c|c|c|c|c|c|c|c|c|c|c|}
\hline \multirow[t]{2}{*}{ Ear } & \multirow[t]{2}{*}{ Group } & \multirow{2}{*}{$\begin{array}{l}250 \mathrm{~Hz} \\
\text { AT }\end{array}$} & \multicolumn{2}{|l|}{$500 \mathrm{~Hz}$} & \multicolumn{2}{|c|}{$1,000 \mathrm{~Hz}$} & \multicolumn{2}{|c|}{$2,000 \mathrm{~Hz}$} & \multirow{2}{*}{$\begin{array}{l}3,000 \mathrm{H}- \\
\mathrm{z} \\
\text { AT }\end{array}$} & \multirow[b]{2}{*}{ BT } & \multicolumn{2}{|c|}{$4,000 \mathrm{~Hz}$} & \multirow{2}{*}{$\begin{array}{l}6,000 \mathrm{~Hz} \\
\text { AT }\end{array}$} & \multirow{2}{*}{$\begin{array}{l}8,000 \mathrm{~Hz} \\
\text { AT }\end{array}$} \\
\hline & & & AT & BT & AT & BT & AT & BT & & & AT & BT & & \\
\hline \multirow[t]{4}{*}{ RE } & CG & $8 \mathrm{~dB}$ & $7.5 \mathrm{~dB}$ & 4.50 & $6.5 \mathrm{~dB}$ & 3.00 & $6 \mathrm{~dB}$ & 3.50 & $4.5 \mathrm{~dB}$ & 3.00 & $5.5 \mathrm{~dB}$ & 3.50 & $12.5 \mathrm{~dB}$ & $8.5 \mathrm{~dB}$ \\
\hline & BEG & $8.3 \mathrm{~dB}$ & $7.2 \mathrm{~dB}$ & 5.00 & $5.5 \mathrm{~dB}$ & 5.00 & $5 \mathrm{~dB}$ & 4.00 & $4.4 \mathrm{~dB}$ & 2.50 & $5 \mathrm{~dB}$ & 3.50 & $12.2 \mathrm{~dB}$ & $7.2 \mathrm{~dB}$ \\
\hline & UEG & $8 \mathrm{~dB}$ & $6.25 \mathrm{~dB}$ & 4.50 & $6.25 \mathrm{~dB}$ & 2.50 & $5 \mathrm{~dB}$ & 2.50 & $3.75 \mathrm{~dB}$ & 3.50 & $6.25 \mathrm{~dB}$ & 4.50 & $10 \mathrm{~dB}$ & $8.75 \mathrm{~dB}$ \\
\hline & $p$-value & 0.589 & 0.109 & 0.944 & 0.738 & 0.209 & 0.528 & 0.767 & 0.247 & 0.797 & 0.425 & 0.914 & 0.061 & 0.634 \\
\hline \multirow[t]{4}{*}{ LE } & CG & $8 \mathrm{~dB}$ & $7 \mathrm{~dB}$ & 4.00 & $5 \mathrm{~dB}$ & 2.00 & $7.5 \mathrm{~dB}$ & 3.00 & $4 \mathrm{~dB}$ & 1.50 & $7 \mathrm{~dB}$ & 3.50 & $8.8 \mathrm{~dB}$ & $6.5 \mathrm{~dB}$ \\
\hline & BEG & $8.8 \mathrm{~dB}$ & $6.1 \mathrm{~dB}$ & 5.50 & $4.4 \mathrm{~dB}$ & 2.00 & $7 \mathrm{~dB}$ & 5.00 & $5 \mathrm{~dB}$ & 1.00 & $5 \mathrm{~dB}$ & 5.00 & $10 \mathrm{~dB}$ & $5 \mathrm{~dB}$ \\
\hline & UEG & $7.5 \mathrm{~dB}$ & $6.25 \mathrm{~dB}$ & 2.00 & $4 \mathrm{~dB}$ & 2.50 & $7.5 \mathrm{~dB}$ & 5.50 & $6.25 \mathrm{~dB}$ & 2.00 & $7 \mathrm{~dB}$ & 2.00 & $7.5 \mathrm{~dB}$ & $6.25 \mathrm{~dB}$ \\
\hline & $p$-value & 0.998 & 0.722 & 0.105 & 0.696 & 0.915 & 0.301 & 0.208 & 0.557 & 0.631 & 0.492 & 0.093 & 0.502 & 0.331 \\
\hline
\end{tabular}

Abbreviations: AT, air threshold; BEG, bilateral experimental group; BT, bone threshold; CG, control group; LE, left ear; RE, right ear; UEG, unilateral experimental group.

Note: Test: analysis of variance (ANOVA).

- Table 8 shows that, in terms of latency, the CG differs from the BEG for the N1, P2, N2 (female), and P300 waves, and the CG differs from the UEG for the P2, N2 (female) and P300 waves. Regarding amplitude, there was a significant difference in both the $\mathrm{N} 1$ and $\mathrm{P} 2$, with the CG differing from the BEG and UEG in the amplitude of these waves evoked by speech.

\section{Discussion}

\section{Homogeneity of the Sample}

In characterizing the sample, we found it to be homogeneous in terms ofgender (male and female) and age group (8-11 and $12-16$ years old). The CG had 40 participants (males $=15$, females $=25 ; 8-11$ years old $=25,12-16$ years old $=15$ ), the BEG had 50 participants ( males $=28$, females $=22$;
$8-11$ years old $=32,12-16$ years old $=18)$, and the UEG had 16 participants ( males $=8$, females $=8 ; 8-11$ years old $=9$, $12-16$ years old $=7$ ).

\section{Sex Effects}

The BEG had a larger number of males compared with the CG, which is in line with the findings of Wertzer et al, ${ }^{23}$ who also identified a higher prevalence of males among children with a history of OM. There is evidence that males have less efficient tubal function than females. ${ }^{24}$

The effect of sex seems to be most evident in the electrophysiological responses, regardless of how they were evoked (verbally or non-verbally). Among females, there was a statistically significant greater prevalence of LLAEP components compared with males. When the elicitor stimulus was speech, the male subjects showed statistically

Table 3 Comparison among the study groups in terms of LLAEP latency, amplitude and sex using toneburst stimuli

\begin{tabular}{|c|c|c|c|c|c|c|c|c|c|c|c|c|}
\hline \multirow[t]{3}{*}{ Wave } & & & \multicolumn{9}{|l|}{ Groups } & \multirow[t]{3}{*}{$p$-value } \\
\hline & & & \multicolumn{3}{|l|}{ CG } & \multicolumn{3}{|l|}{ BEG } & \multicolumn{3}{|l|}{ UEG } & \\
\hline & Measure & Sex & $\sum$ & Med & SD & $\sum$ & Med & SD & $\sum$ & Med & SD & \\
\hline \multirow[t]{2}{*}{ N1 } & LAT & $\begin{array}{l}M \\
F\end{array}$ & $\begin{array}{l}109.08 \\
105.87\end{array}$ & $\begin{array}{l}102.83 \\
107.99\end{array}$ & $\begin{array}{l}23.45 \\
23.15\end{array}$ & $\begin{array}{l}110.83 \\
106.35\end{array}$ & $\begin{array}{l}109.03 \\
103.82\end{array}$ & $\begin{array}{l}21.11 \\
17.19\end{array}$ & $\begin{array}{l}108.83 \\
104.98\end{array}$ & $\begin{array}{l}114.75 \\
102.78\end{array}$ & $\begin{array}{l}23.48 \\
20.38\end{array}$ & 0.982 \\
\hline & AMP & $\begin{array}{l}M \\
F\end{array}$ & $\begin{array}{l}3.33 \\
3.68\end{array}$ & $\begin{array}{l}3.35 \\
3.37\end{array}$ & $\begin{array}{l}1.09 \\
1.90\end{array}$ & $\begin{array}{l}2.29 \\
3.71\end{array}$ & $\begin{array}{l}1.67 \\
3.26\end{array}$ & $\begin{array}{l}1.64 \\
2.41\end{array}$ & $\begin{array}{l}2.49 \\
2.93\end{array}$ & $\begin{array}{l}1.84 \\
2.59\end{array}$ & $\begin{array}{l}1.71 \\
1.65\end{array}$ & 0.483 \\
\hline \multirow[t]{2}{*}{ P2 } & LAT & $\begin{array}{l}M \\
F\end{array}$ & $\begin{array}{l}150.36 \\
149.48\end{array}$ & $\begin{array}{l}145.46 \\
145.98\end{array}$ & $\begin{array}{l}22.61 \\
27.56\end{array}$ & $\begin{array}{l}159.31 \\
161.46\end{array}$ & $\begin{array}{l}157.43 \\
161.08\end{array}$ & $\begin{array}{l}26.83 \\
20.80\end{array}$ & $\begin{array}{l}161.80 \\
156.39\end{array}$ & $\begin{array}{l}161.60 \\
160.04\end{array}$ & $\begin{array}{l}27.34 \\
20.03\end{array}$ & 0.368 \\
\hline & AMP & $\begin{array}{l}M \\
F\end{array}$ & $\begin{array}{l}3.73 \\
3.31\end{array}$ & $\begin{array}{l}3.54 \\
3.52\end{array}$ & $\begin{array}{l}1.43 \\
1.33\end{array}$ & $\begin{array}{l}3.11 \\
4.50\end{array}$ & $\begin{array}{l}2.28 \\
4.41\end{array}$ & $\begin{array}{l}2.44 \\
2.90\end{array}$ & $\begin{array}{l}3.38 \\
2.73\end{array}$ & $\begin{array}{l}2.55 \\
2.11\end{array}$ & $\begin{array}{l}2.83 \\
2.04\end{array}$ & $0.006^{*}$ \\
\hline \multirow[t]{2}{*}{$\mathrm{N} 2$} & LAT & $\begin{array}{l}M \\
F\end{array}$ & $\begin{array}{l}211.11 \\
195.67\end{array}$ & $\begin{array}{l}206.88 \\
188.66\end{array}$ & $\begin{array}{l}30.16 \\
32.07\end{array}$ & $\begin{array}{l}214.95 \\
225.15\end{array}$ & $\begin{array}{l}217.81 \\
223.54\end{array}$ & $\begin{array}{l}38.65 \\
30.75\end{array}$ & $\begin{array}{l}217.03 \\
214.75\end{array}$ & $\begin{array}{l}220.94 \\
221.46\end{array}$ & $\begin{array}{l}40.22 \\
33.53\end{array}$ & $0.048^{*}$ \\
\hline & AMP & $\begin{array}{l}M \\
F\end{array}$ & $\begin{array}{l}4.92 \\
4.65\end{array}$ & $\begin{array}{l}4.3 \\
4.33\end{array}$ & $\begin{array}{l}2.41 \\
2.27\end{array}$ & $\begin{array}{l}3.37 \\
4.39\end{array}$ & $\begin{array}{l}2.01 \\
3.44\end{array}$ & $\begin{array}{l}3.08 \\
3.71\end{array}$ & $\begin{array}{l}3.46 \\
3.10\end{array}$ & $\begin{array}{l}2.94 \\
2.66\end{array}$ & $\begin{array}{l}2.15 \\
2.26\end{array}$ & 0.162 \\
\hline \multirow[t]{2}{*}{ P300 } & LAT & $\begin{array}{l}M \\
F\end{array}$ & $\begin{array}{l}315.01 \\
318.62\end{array}$ & $\begin{array}{l}314.63 \\
321.39\end{array}$ & $\begin{array}{l}27.58 \\
33.30\end{array}$ & $\begin{array}{l}323.36 \\
336.49\end{array}$ & $\begin{array}{l}317.23 \\
332.32\end{array}$ & $\begin{array}{l}36.62 \\
40.98\end{array}$ & $\begin{array}{l}321.29 \\
333.89\end{array}$ & $\begin{array}{l}318.79 \\
337.53\end{array}$ & $\begin{array}{l}31.62 \\
48.16\end{array}$ & 0.677 \\
\hline & AMP & $\begin{array}{l}M \\
F\end{array}$ & $\begin{array}{l}6.08 \\
5.18\end{array}$ & $\begin{array}{l}6.01 \\
4.42\end{array}$ & $\begin{array}{l}1.88 \\
2.23\end{array}$ & $\begin{array}{l}5.30 \\
5.57\end{array}$ & $\begin{array}{l}4.82 \\
4.53\end{array}$ & $\begin{array}{l}2.41 \\
2.56\end{array}$ & $\begin{array}{l}5.55 \\
5.47\end{array}$ & $\begin{array}{l}5.22 \\
5.57\end{array}$ & $\begin{array}{l}2.44 \\
1.61\end{array}$ & 0.630 \\
\hline
\end{tabular}

Abbreviations: $\sum$, average; AMP, amplitude; BEG, bilateral experimental group; CG, control group; F, female; LAT, latency; M, male; Med, median; SD, standard deviation; UEG, unilateral experimental group. ${ }^{*}=p \leq 0.05$. 
Table 4 Comparison among the study groups in terms of LLAEP latency, amplitude and sex using toneburst stimuli

\begin{tabular}{|c|c|c|c|c|c|c|c|c|c|c|c|c|}
\hline \multirow[t]{3}{*}{ Wave } & \multirow{3}{*}{ Measure } & & \multicolumn{9}{|l|}{ Groups } & \multirow[t]{3}{*}{$p$-value } \\
\hline & & & \multicolumn{3}{|l|}{ CG } & \multicolumn{3}{|l|}{ BEG } & \multicolumn{3}{|l|}{ UEG } & \\
\hline & & & $\sum$ & Med & DP & $\sum$ & Med & DP & $\sum$ & Med & DP & \\
\hline \multirow[t]{2}{*}{ N1 } & LAT & & 107.08 & 105.38 & 23.17 & 108.86 & 106.42 & 19.52 & 106.91 & 105.9 & 21.72 & 0.906 \\
\hline & AMP & & 3.07 & 3.32 & 1.11 & 2.08 & 1.84 & 1.35 & 1.76 & 1.63 & 1.26 & 0.116 \\
\hline \multirow[t]{2}{*}{ P2 } & LAT & & 149.81 & 145.46 & 25.67 & 160.26 & 159.52 & 24.27 & 159.09 & 161.08 & 23.73 & $0.018^{*}$ \\
\hline & AMP & $\begin{array}{l}M \\
F\end{array}$ & $\begin{array}{l}3.73 \\
3.31\end{array}$ & $\begin{array}{l}3.54 \\
3.52\end{array}$ & $\begin{array}{l}1.43 \\
1.33\end{array}$ & $\begin{array}{l}3.11 \\
4.50\end{array}$ & $\begin{array}{l}2.28 \\
4.41\end{array}$ & $\begin{array}{l}2.44 \\
2.90\end{array}$ & $\begin{array}{l}3.38 \\
2.73\end{array}$ & $\begin{array}{l}2.55 \\
2.11\end{array}$ & $\begin{array}{l}2.83 \\
2.04\end{array}$ & $\begin{array}{l}0.336 \\
0.006^{*}\end{array}$ \\
\hline \multirow[t]{2}{*}{ N2 } & LAT & $\begin{array}{l}\mathrm{M} \\
\mathrm{F}\end{array}$ & $\begin{array}{l}211.11 \\
195.67\end{array}$ & $\begin{array}{l}206.88 \\
188.66\end{array}$ & $\begin{array}{l}30.16 \\
32.07\end{array}$ & $\begin{array}{l}214.95 \\
225.15\end{array}$ & $\begin{array}{l}217.81 \\
223.54\end{array}$ & $\begin{array}{l}38.65 \\
30.75\end{array}$ & $\begin{array}{l}217.03 \\
214.75\end{array}$ & $\begin{array}{l}220.94 \\
221.46\end{array}$ & $\begin{array}{l}40.22 \\
33.53\end{array}$ & $\begin{array}{l}0.750 \\
<0.001\end{array}$ \\
\hline & AMP & & 3.49 & 3.36 & 1.23 & 4.08 & 3.48 & 3.03 & 3.30 & 2.89 & 1.97 & 0.405 \\
\hline \multirow[t]{2}{*}{ P300 } & LAT & & 317.26 & 320.35 & 31.14 & 328.99 & 324.52 & 38.90 & 327.79 & 331.28 & 40.83 & 0.187 \\
\hline & AMP & & 5.52 & 5.13 & 2.14 & 5.42 & 4.66 & 2.47 & 5.56 & 5.33 & 2.02 & 0.914 \\
\hline
\end{tabular}

Abbreviations: $\sum$, average; AMP, amplitude; BEG, bilateral experimental group; CG, control group; F, female; LAT, latency; M, male; Med, median; SD, standard deviation; UEG, unilateral experimental group; ${ }^{*}=p \leq 0.05$.

Table 5 Comparison between pairs of groups in terms of LLAEP latency and amplitude using toneburst stimuli

\begin{tabular}{|l|l|l|l|l|l|l|}
\hline & \multicolumn{4}{|l|}{ LATENCY } & \multicolumn{2}{l|}{ AMPLITUDE } \\
\hline & \multicolumn{2}{|l|}{ P2 } & N2 (female) & \multicolumn{2}{l|}{ P2 (female) } \\
\hline Group & Difference & $p$-value & Difference & $p$-value & Difference & $p$-value \\
\hline CG $\times$ BEG & 12.125 & $\mathbf{0 . 0 5 0 ^ { * }}$ & 28.584 & $<\mathbf{0 . 0 0 1}^{*}$ & 1.197 & 0.083 \\
\hline UEG $\times$ BEG & 8.147 & 0.470 & 11.617 & 0.445 & 1.779 & 0.058 \\
\hline UEG $\times$ CG & 3.978 & 0.843 & 16.967 & 0.172 & 0.582 & 0.935 \\
\hline
\end{tabular}

Abbreviations: BEG, bilateral experimental group; CG, control group; UEG, unilateral experimental group. ${ }^{*}=p \leq 0.05$.

Table 6 Comparison among the study groups in terms of LLAEP latency and amplitude using speech stimuli

\begin{tabular}{|c|c|c|c|c|c|c|c|c|c|c|c|c|}
\hline \multirow[t]{3}{*}{ Waves } & \multirow[t]{3}{*}{ Measure } & & \multicolumn{10}{|l|}{ Groups } \\
\hline & & & \multicolumn{3}{|l|}{ CG } & \multicolumn{3}{|l|}{ BEG } & \multicolumn{3}{|l|}{ UEG } & \multirow[b]{2}{*}{$p$-value } \\
\hline & & & $\sum$ & Med & SP & $\sum$ & Med & SP & $\sum$ & Med & SP & \\
\hline \multirow[t]{2}{*}{ N1 } & AMP & $\begin{array}{l}M \\
F\end{array}$ & $\begin{array}{l}3.33 \\
3.67\end{array}$ & $\begin{array}{l}3.35 \\
3.37\end{array}$ & $\begin{array}{l}1.09 \\
1.90\end{array}$ & $\begin{array}{l}2.29 \\
3.71\end{array}$ & $\begin{array}{l}1.67 \\
3.26\end{array}$ & $\begin{array}{l}1.64 \\
2.41\end{array}$ & $\begin{array}{l}2.49 \\
2.93\end{array}$ & $\begin{array}{l}1.84 \\
2.59\end{array}$ & $\begin{array}{l}1.71 \\
1.65\end{array}$ & 0.730 \\
\hline & LAT & $\begin{array}{l}M \\
F\end{array}$ & $\begin{array}{l}117.11 \\
107.51\end{array}$ & $\begin{array}{l}110.56 \\
103.82\end{array}$ & $\begin{array}{l}28.27 \\
23.41\end{array}$ & $\begin{array}{l}119.52 \\
124.62\end{array}$ & $\begin{array}{l}118.92 \\
116.83\end{array}$ & $\begin{array}{l}23.55 \\
25.67\end{array}$ & $\begin{array}{l}120.09 \\
125.36\end{array}$ & $\begin{array}{l}114.23 \\
119.43\end{array}$ & $\begin{array}{l}24.72 \\
23.24\end{array}$ & 0.130 \\
\hline \multirow[t]{2}{*}{ P2 } & AMP & $\begin{array}{l}M \\
F\end{array}$ & $\begin{array}{l}3.73 \\
3.31\end{array}$ & $\begin{array}{l}3.54 \\
3.52\end{array}$ & $\begin{array}{l}1.43 \\
1.33\end{array}$ & $\begin{array}{l}3.11 \\
4.50\end{array}$ & $\begin{array}{l}2.28 \\
2.44\end{array}$ & $\begin{array}{l}2.44 \\
2.91\end{array}$ & $\begin{array}{l}3.38 \\
2.73\end{array}$ & $\begin{array}{l}2.55 \\
2.11\end{array}$ & $\begin{array}{l}2.83 \\
2.04\end{array}$ & 1.061 \\
\hline & LAT & $\begin{array}{l}M \\
F\end{array}$ & $\begin{array}{l}159.99 \\
149.81\end{array}$ & $\begin{array}{l}154.31 \\
154.31\end{array}$ & $\begin{array}{l}23.34 \\
27.61\end{array}$ & $\begin{array}{l}167.44 \\
171.30\end{array}$ & $\begin{array}{l}172.01 \\
171.49\end{array}$ & $\begin{array}{l}25.17 \\
25.24\end{array}$ & $\begin{array}{l}174.35 \\
163.16\end{array}$ & $\begin{array}{l}171.49 \\
159.02\end{array}$ & $\begin{array}{l}25.18 \\
17.28\end{array}$ & 0.131 \\
\hline \multirow[t]{2}{*}{$\mathrm{N} 2$} & AMP & $\begin{array}{l}M \\
F\end{array}$ & $\begin{array}{l}4.92 \\
4.65\end{array}$ & $\begin{array}{l}4.30 \\
4.33\end{array}$ & $\begin{array}{l}2.41 \\
2.2\end{array}$ & $\begin{array}{l}3.37 \\
4.39\end{array}$ & $\begin{array}{l}2.01 \\
3.08\end{array}$ & $\begin{array}{l}3.08 \\
3.71\end{array}$ & $\begin{array}{l}3.46 \\
3.09\end{array}$ & $\begin{array}{l}2.94 \\
2.66\end{array}$ & $\begin{array}{l}2.15 \\
2.26\end{array}$ & 1.837 \\
\hline & LAT & $\begin{array}{l}M \\
F\end{array}$ & $\begin{array}{l}214.52 \\
196.41\end{array}$ & $\begin{array}{l}225.10 \\
199.07\end{array}$ & $\begin{array}{l}29.38 \\
37.59\end{array}$ & $\begin{array}{l}223.85 \\
231.06\end{array}$ & $\begin{array}{l}230.31 \\
232.39\end{array}$ & $\begin{array}{l}29.31 \\
21.89\end{array}$ & $\begin{array}{l}223.81 \\
225.10\end{array}$ & $\begin{array}{l}236.55 \\
226.66\end{array}$ & $\begin{array}{l}29.18 \\
18.04\end{array}$ & $0.023^{*}$ \\
\hline \multirow[t]{2}{*}{ P300 } & AMP & $\begin{array}{l}M \\
F\end{array}$ & $\begin{array}{l}6.08 \\
5.18\end{array}$ & $\begin{array}{l}6.01 \\
4.42\end{array}$ & $\begin{array}{l}1.88 \\
2.23\end{array}$ & $\begin{array}{l}5.30 \\
5.57\end{array}$ & $\begin{array}{l}4.82 \\
2.41\end{array}$ & $\begin{array}{l}2.41 \\
2.56\end{array}$ & $\begin{array}{l}5.55 \\
5.57\end{array}$ & $\begin{array}{l}5.22 \\
5.47\end{array}$ & $\begin{array}{l}2.44 \\
1.61\end{array}$ & 0.463 \\
\hline & LAT & $\begin{array}{l}M \\
F\end{array}$ & $\begin{array}{l}318.22 \\
315.76\end{array}$ & $\begin{array}{l}321.03 \\
312.02\end{array}$ & $\begin{array}{l}22.21 \\
33.64\end{array}$ & $\begin{array}{l}343.49 \\
360.09\end{array}$ & $\begin{array}{l}328.68 \\
358.79\end{array}$ & $\begin{array}{l}43.98 \\
39.57\end{array}$ & $\begin{array}{l}352.44 \\
351.00\end{array}$ & $\begin{array}{l}346.90 \\
331.28\end{array}$ & $\begin{array}{l}46.01 \\
51.88\end{array}$ & 0.248 \\
\hline
\end{tabular}

Abbreviations: $\sum$, average; AMP, amplitude; BEG, bilateral experimental group; CG, control group; SD, standard deviation; F, female; LAT, latency; M, male; Med, median; UEG, unilateral experimental group. ${ }^{*}=p \leq 0.05$. 
Table 7 Comparison between groups of schoolchildren for LLAEP latency and amplitude using speech stimuli

\begin{tabular}{|c|c|c|c|c|c|c|c|c|c|c|c|}
\hline \multirow[t]{3}{*}{ Waves } & \multirow[t]{3}{*}{ Measure } & \multicolumn{10}{|l|}{ Groups } \\
\hline & & \multicolumn{3}{|l|}{ CG } & \multicolumn{3}{|l|}{ BEG } & \multicolumn{3}{|l|}{ UEG } & \multirow[b]{2}{*}{$p$-value } \\
\hline & & $\sum$ & Med & SD & $\sum$ & Med & SD & $\sum$ & Med & SD & \\
\hline \multirow[t]{2}{*}{ N1 } & AMP & 3.07 & 3.32 & 1.11 & 2.08 & 1.84 & 1.81 & 1.76 & 1.63 & 1.26 & $<0.001^{*}$ \\
\hline & LAT & 111.11 & 107.47 & 25.60 & 121.78 & 116.83 & 24.52 & 122.72 & 119.43 & 23.75 & $0.011^{*}$ \\
\hline \multirow[t]{2}{*}{ P2 } & AMP & 3.79 & 3.71 & 1.55 & 2.94 & 2.61 & 1.92 & 2.59 & 2.46 & 1.49 & $<0.001^{*}$ \\
\hline & LAT & 153.65 & 154.31 & 26.41 & 169.15 & 172.01 & 25.14 & 168.76 & 166.28 & 21.99 & $<0.001^{*}$ \\
\hline \multirow[t]{3}{*}{ N2 } & AMP & 3.49 & 3.36 & 1.24 & 4.08 & 3.03 & 3.48 & 3.30 & 2.89 & 1.97 & 0.124 \\
\hline & LAT M & 214.52 & 225.10 & 29.38 & 223.85 & 230.31 & 29.31 & 223.81 & 236.55 & 29.18 & 0.566 \\
\hline & LAT F & 196.41 & 199.07 & 37.59 & 231.06 & 232.39 & 21.89 & 225.10 & 226.66 & 18.04 & $0.001^{*}$ \\
\hline \multirow[t]{2}{*}{ P300 } & AMP & 3.88 & 3.53 & 1.36 & 3.94 & 3.64 & 2.01 & 3.68 & 3.36 & 1.34 & 0.706 \\
\hline & LAT & 316.68 & 317.75 & 29.74 & 350.71 & 341.69 & 42.69 & 351.70 & 339.61 & 48.31 & $<0.001^{*}$ \\
\hline
\end{tabular}

Abbreviations: $\sum$, average; AMP, amplitude; BEG, bilateral experimental group; CG, control group; SD, standard deviation; F, female; LAT, latency; M, male; Med, median; UEG, unilateral experimental group. ${ }^{*}=p \leq 0.05$.

significant differences in responses only in the latency of the $\mathrm{N} 2$ component. For females, on the other hand, differences in $\mathrm{N} 2$ wave latencies were observed using both tone bursts and speech. These data corroborate a recent study ${ }^{25}$ that concluded that gender had a significant effect on LLAEP responses.

In our study, the CG males had a higher mean N2 wave latency (increased latency values) than that of the females. The same occurred in the UEG. However, the opposite was observed in the BEG, in which the mean latency was higher for girls. Our data agree with the literature regarding the difference in N2 wave latency between the sexes; ${ }^{26,27}$ however, further studies are still needed to determine whether these differences are due to neuroanatomical differences in the auditory pathway.

\section{Unilateral and Bilateral Effects}

The smaller number of participants in the UEG compared with the BEG is consistent with the findings of Casebrant et al, ${ }^{17}$ who reported a higher prevalence of bilateral alteration in cases of OME. Similarly, Maruthy and Mannarukrishnaiah $^{18}$ found that among 30 children, only 4 had unilateral impairment, with the rest affected bilaterally. The rate of contralateral ear involvement in ears affected by OM has been recorded to be of $\sim 75 \%,{ }^{19}$ and it increases to as much as $91 \%$ in patients with a history of OM. ${ }^{20}$ Therefore, Silva et $\mathrm{al}^{28}$ recommend that, when examining ears by computed tomography, both ears should be tested, since contralateral ear involvement in OM promotes a high prevalence of abnormalities.

\section{Tonal Auditory Thresholds}

The analysis of average auditory thresholds showed that there was no statistically significant difference between the groups from 250 to $8,000 \mathrm{~Hz}$, even though all participants in the three groups (CG, BEG, and UEG) had mean auditory thresholds lower than $15 \mathrm{~dB}^{29}$ The finding of normal responses among the groups is essential before one can claim that the alterations identified electrophysiologically were due to a history of OM. A further conclusion is that the results of the present study were not affected by differences regarding the LLAEPs in the peripheral auditory nervous system.

\section{LLAEPs Using a Non-Verbal Stimulus (a Toneburst) in Patients with a History of Unilateral and Bilateral Otitis Media}

The analysis of the AEP responses using toneburst stimuli showed that there was no statistically significant difference by ear or age; however, a difference in the P2 and N2 components was observed regarding sex. These components represent the neural activation of sites in the supratemporal lateral/frontal plane and from the primary auditory cortex, both considered responsible for the exogenous portion of the event-related potential (ERP). The literature emphasizes that these components reflect the pre-attentional coding of the

Table 8 Comparison between pairs of groups in terms of LLAEP latency and amplitude using speech stimuli

\begin{tabular}{|c|c|c|c|c|c|c|c|c|c|c|c|c|}
\hline \multirow[b]{3}{*}{ Groups } & \multicolumn{8}{|l|}{ LATENCY } & \multicolumn{4}{|l|}{ AMPLITUDE } \\
\hline & \multicolumn{2}{|l|}{ N1 } & \multicolumn{2}{|l|}{ P2 } & \multicolumn{2}{|c|}{ N2 (female) } & \multicolumn{2}{|l|}{ P300 } & \multicolumn{2}{|l|}{ N1 } & \multicolumn{2}{|l|}{ P2 } \\
\hline & Difference & $p$-value & Difference & $p$-value & Difference & $p$-value & Difference & $p$-value & Difference & $p$-value & Difference & $p$-value \\
\hline CG $x$ BEG & 10.330 & $0.016^{*}$ & 22.673 & $<0.001^{*}$ & 31.337 & $<0.001^{*}$ & 34.159 & $<0.001^{*}$ & 0.990 & $<0.001^{*}$ & 0.808 & $0.004^{*}$ \\
\hline UEG $\times$ BEG & 0.878 & 0.983 & 2.517 & 0.906 & 10.530 & 0.463 & 0.948 & 0.992 & 0.303 & 0.448 & 0.326 & 0.601 \\
\hline UEG x CG & 11.208 & 0.080 & 20.156 & $0.003^{*}$ & 20.806 & $0.049^{*}$ & 35.107 & $<0.001^{*}$ & 1.294 & $<0.001^{*}$ & 1.135 & $0.003^{*}$ \\
\hline
\end{tabular}

Abbreviations: BEG, bilateral experimental group; CG, control group; UEG, unilateral experimental group. ${ }^{*}=p \leq 0.05$. 
auditory stimuli. More specifically, the N2 component represents acoustic processing performed up to the highest portion of the CANS, while the P2 component arises from the initial process of categorization and perception of rare stimuli, and is linked to the recognition of the duration of a sound stimulus. ${ }^{30,31}$

Changes in the processing of auditory information such as frequency, time, and duration are reported in children with phonological and language disorders. ${ }^{32}$ These changes are often associated with problems due to OM. ${ }^{11,33,34}$ However, there are a few studies that have studied LLAEP responses in children with a history of OM.

We found that children who had a history of unilateral or bilateral $\mathrm{OM}$ presented poorer performance (increase in latency values and decrease in amplitude values) when compared with the CG, specifically in the P2 amplitude among females. Compared with other potentials, P2 amplitude is extremely valuable in AEP analyses because it provides a measure of the number of neurons activated by auditory stimulation. In the case of children with recurrent $\mathrm{OM}$, it can indicate long-term damage due to auditory deprivation in the thalamic and cortical regions of the CANS.

Our findings are similar to those of Maruthy and Mannarukrishnaiah ${ }^{18}$ and Shaffer ${ }^{35}$ with regard to the presence of changes in LLAEPs in children with a history of OM. However, in the present study, we found prolongation of latency only in the P2 and N2 waves (and in females) compared with the CG responses. In comparison, Maruthy and Mannarukrishnaiah ${ }^{18}$ found that all components of the LLAEPs (P1, N1, P2, and N2) were significantly longer in children with a history of OME. Shaffer ${ }^{35}$ saw an increase in the latencies of $\mathrm{N} 1$ and $\mathrm{P} 2$ associated with the absence of the P300 wave in the majority of the children evaluated. In the UEG, however, no statistically significant changes were found in the LLAEPs when compared with the CG responses. Concerning amplitudes, our study also agreed with Maruthy and Mannarukrishnaiah, ${ }^{18}$ since no statistically significant difference in amplitudes was observed between the groups.

The present study did not find differences in the latencies of the LLAEPs in the UEG compared with the CG. Nevertheless, it should be remembered that sound stimuli are sent to the brain through ipsilateral and contralateral auditory pathways, so information on location, intensity, time, and duration requires processing by two ears. The alterations found in the present study can be explained by the fact that the children had some degree of hearing deprivation; it can be surmised that they therefore had a somewhat inefficient neuronal activation, perhaps due to impaired myelinisation of the nerve fibers.

In the present study, we used LLAEPs to evaluate the neurophysiological activity of the CANS in children with hearing loss. Compared with their peers with normal hearing, we observed that these children underwent changes in the latency and amplitudes of the LLAEP components: they have more poorly-defined N1 and P2 waves associated with a reduction in amplitudes and extended N2 wave latency. ${ }^{36}$ The present study highlights the importance of the integrity of CANS structures to provide a normal auditory experience, especially during the critical period for language development. A change in CANS during this critical period can lead to an abnormal pattern of LLAEP responses. Otitia media provides a temporary or even permanent increase in hearing loss that can impair the auditory pathways and affect the maturation of the entire auditory system. The literature shows that children who undergo some type of intervention, even if early, either through the use of hearing aids or cochlear implants, retain normal neurophysiological development. $^{36}$

Children with a history of OM should therefore be monitored periodically, even if they present auditory thresholds within normal limits, since diminished stimulation or experience of abnormal day-to-day sound stimuli can affect the way the CANS processes information. This monitoring should also include children with unilateral impairment.

The differences found among the different studies can be explained by the wide diversity in the way LLAEPs are conducted. The differences can include the stimulation parameters used (such as frequency, duration, or intensity of frequent and rare stimuli, use of different filters, or analysis techniques), or the mode of analysis employed (identification of N1, P2, and N2 components in the frequent stimulus tracing or identification of the P300 component in all traces). Thus, even though LLAEPs are considered a potential objective way of evaluating auditory function, there are many controversies and possibilities for its collection and analysis, and these can lead to difficulties in interpreting and comparing results among studies. For this reason, it would be an important advance if the guidelines could be developed to standardize parameters and guarantee the quality of the results obtained.

\section{LLAEPs Using a Verbal Stimulus (Speech) in Patients with a History of Unilateral and Bilateral Otitis Media}

The present study has demonstrated that children with a documented history of bilateral OM have extended latencies for all speech-evoked waves - N1, P2, N2 (females), and P300. In children with a history of unilateral OM, however, we found extended latencies for the P2 and P300 waves only. Regarding the amplitude values of the LLAEPs with a speech stimulus, the UEG and BEG children had lower N1 and P2 amplitude of response.

According to Duncan et al, ${ }^{37}$ perceptual and attentional variables may affect the $\mathrm{P} 300$ responses, although the physical characteristics of the sound stimuli seem to have no effect. These findings were obtained among healthy individuals, and the responses were confirmed in the CG in the present study. Our findings, however, did show that a verbal stimulus was able to modify the P300 component in individuals with a history of OM. Therefore, in children with a history of pathologies, the electrophysiological evaluation with different sound stimuli is recommended. In the literature to date, no studies have investigated the effect of OM on LLAEP responses with speech stimuli. The verbal stimulus used in LLAEPs provides additional information about the biological processes involved in speech processing, providing 
information that is complementary to that obtained by the standard behavioral evaluation. ${ }^{15,16}$

In a study with children with language-specific impairment, ${ }^{38}$ the P300 latency was found to be the same when the evaluation was performed with speech as for non-verbal sounds; however, when the amplitude values were compared with normal children, they were the same only when speech stimuli were used. The present study achieved similar results, since the comparison of LLAEPs using non-verbal and verbal stimuli could identify neurophysiological alterations resulting from OM. Nevertheless, for the UEG children, only the speech LLAEPs were able to differentiate them from the CG in terms of latency. However, our data differ regarding the reduction in amplitude, since there was a decrease in amplitude both in response to nonverbal and verbal sounds.

The processing of speech is much more complex than the coding of non-verbal sounds, and it depends on the proper functioning of different structures along the auditory pathway. In addition, researchers have pointed out that impairments in auditory perception can lead to language and learning problems. Otitis media, in turn, causes impairment to speech perception, prompting failure to recognize sounds (due to lesser discrimination, storage, and memory). Therefore, the accurate measurement of how LLAEPs change with verbal and non-verbal stimuli may provide an important clue to whether OM is causing speech recognition problems.

In our investigation of latency, children with bilateral impairment presented alterations in a greater number of LLAEP components when verbal stimuli were used (N1, P2, N2, and P300) compared with when non-verbal ones were used (P2 and P300). The P2 and P300 waves are related to functions of vital importance for the processing of auditory information. Research has shown that the P2 wave has a role in determining whether ipsilateral or contralateral stimulation is occurring, ${ }^{26}$ a reason why this component is different in both unilateral and bilateral cases of OM. The present study was able to demonstrate that the occurrence of unilateral OM, even when demonstrating a good hearing condition, also showed a significant abnormality in the functioning of the system.

Long-latency AEPs can be applied in two clinical conditions: (i) in the monitoring of the maturational process of normal individuals; and (ii) in evaluating individuals with pathologies to identify disorders in cognitive function. A detailed evaluation might assist in predicting whether vulnerable individuals could develop changes in their attentional processes. ${ }^{37}$ Children with a history of OM might benefit from an LLAEP evaluation, since it has good diagnostic power, therefore enabling the implementation of a hearing remediation program.

\section{Conclusion}

Children who had suffered OME in the first six years of life and who had undergone myringotomy for the placement of a ventilation tube, either unilaterally or bilaterally, presented worse performance in their electrophysiological responses to verbal and non-verbal stimuli compared with children and adolescents with no past history of OME.

\section{Funding}

This work was supported by Coordenação de Aperfeiçoamento de Pessoal de Nível Superior (CAPES) (01-P-4346/ 2015) and Fundação de Apoio à Pesquisa do Estado de São Paulo (FAPESP) (889074). The funders had no role in the study design, data collection and analysis, the decision to publish, or the preparation of the manuscript.

\section{Conflict of Interests}

The authors have none to declare.

\section{References}

1 Hungria H. Otite media serosa/secretora. In: Hungria H, editor. Otorrinolaringologia. Rio de Janeiro: Guanabara-Koogan; 1995 : 335-341

2 ASHA. (Central) Auditory Processing Disorders. Working group on Auditory Processing Disorders. Technical Report p1-20 [Internet]. 2005

3 Klausen O, Møller P, Holmefjord A, Reisaeter S, Asbjørnsen A. Lasting effects of otitis media with effusion on language skills and listening performance. Acta Otolaryngol Suppl 2000;543:73-76

4 Knudsen EI. Sensitive periods in the development of the brain and behavior. J Cogn Neurosci 2004;16(08):1412-1425

5 Stephenson H, Haggard M, Ziellius G, Van Den Broek P, Schilder A. Prevalence of tympanogram assymetrics and fluctuations in otitis media with effusion: implications for binaural hearing. Audiology 1993;32(03):164-174

6 Griffin GH, Flynn C, Bailey RE, Schultz JK. Antihistamines and/or decongestants for otitis media with effusion (OME) in children. Cochrane Database Syst Rev 2006;18(04):CD003423

7 Williamson I. Otitis media with effusion in children. BMJ Clin Evid 2011

8 Ginsberg I, White T. Considerações otológicas em audiologia. In: Katz J, editor. Tratado de Audiologia 1999:6-23

9 Gravel JS, Wallace IF, Ruben RJ. Auditory consequences of early mild hearing loss associated with otitis media. Acta Otolaryngol 1996;116(02):219-221

10 Campbell N, Hugo R, Uys I, Hanekom J, Millard S. Early recurrent otitis media, language and central auditory processing in children. S Afr J Commun Disord 1995;42:73-84

11 Gravel JS, Roberts JE, Roush J, et al. Early otitis media with effusion, hearing loss, and auditory processes at school age. Ear Hear 2006; 27(04):353-368

12 Burkard R, Don M, Eggermont J. Auditory Evoked Potentials: Basic Principles and Clinical Application. Lippincott Williams \& Wilkins; 2007

13 Donchin E, Coles M. Is the P300 component a manifestation of context updating? Behav Brain Sci 1988;11(03):357-374

14 Picton TW. The P300 wave of the human event-related potential. J Clin Neurophysiol 1992;9(04):456-479

15 Oates PA, Kurtzberg D, Stapells DR. Effects of sensorineural hearing loss on cortical event-related potential and behavioral measures of speech-sound processing. Ear Hear 2002;23(05): 399-415

16 Martin B, Tremblay K, Korczack P. Speech evoked potential: from the laboratory to the clinic. Ear Hear 2002;23(05):399-415

17 Casselbrant ML, Brostoff LM, Cantekin EI, et al. Otitis media with effusion in preschool children. Laryngoscope 1985;95(04): 428-436

18 Maruthy S, Mannarukrishnaiah J. Effect of early onset otitis media on brainstem and cortical auditory processing. Behav Brain Funct 2008;4:17 
19 Costa S, Cruz O, Oliveira J. Otorrinolaringologia: princípios e prática. Art Med 2006

20 Rosito LP, da Costa SS, Schachern PA, Dornelles C, Cureoglu S, Paparella MM. Contralateral ear in chronic otitis media: a histologic study. Laryngoscope 2007;117(10):1809-1814

21 Jerger J. Clinical experience with impedance audiometry. Arch Otolaryngol 1970;92(04):311-324

22 Jasper $\mathrm{H}$. The ten-twenty system of the International Federation. Electroencephalogr Clin Neurophysiol 1958;10:371-375

23 Wertzer H, Pagan L, Galea E, Papp A. Características fonológicas de crianças com transtorno fonológico com e sem histórico de otite média. Rev Soc Bras Fonoaudiol 2007;12(01):41-47

24 Sipilä M, Pukander J, Karma P. Incidence of acute otitis media up to the age of $11 / 2$ years in urban infants. Acta Otolaryngol 1987;104 (1-2):138-145

25 Bourisly AK, Pothen A. Influence of sex on P300: an event-related potential electrophysiological study. Neuroreport 2016;27(03): 172-179

26 Baumann SB, Rogers RL, Papanicolaou AC, Saydjari CL. Intersession replicability of dipole parameters from three components of the auditory evoked magnetic field. Brain Topogr 1990;3(02): 311-319

27 Polich J. Normal variation of P300 from auditory stimuli. Electroencephalogr Clin Neurophysiol 1986;65(03):236-240

28 Silva MN, Muller JdosS, Selaimen FA, Oliveira DS, Rosito LP, Costa SS. Tomographic evaluation of the contralateral ear in patients with severe chronic otitis media. Rev Bras Otorrinolaringol (Engl Ed) 2013;79(04):475-479
29 Northern J, Downs M. Avaliação Auditiva Comportamental. In: Northern J, Downs M, editors. Audição na infância. Rio de Janeiro: Guanabara-Koogan; 2005:129-67

30 Squires K, Hillyard S, Lindsay P. Cortical potentials evoked by feedback confirming and disconfirming an auditory discrimination. Percept Psychophys 1973;13:25-31

31 Hillyard S, Picton T Electrophysiology of cognition 1987

32 Tonnquist-Uhlén I. Topography of auditory evoked cortical potentials in children with severe language impairment. Scand Audiol Suppl 1996;44(44):1-40

33 Hall JW, Grose JH, Buss E, Dev MB, Drake AF, Pillsbury HC. The effect of otitis media with effusion on perceptual masking. Arch Otolaryngol Head Neck Surg 2003;129(10):1056-1062

34 Moore DR. Auditory processing disorders: acquisition and treatment. J Commun Disord 2007;40(04):295-304

35 Saffer EK. Auditory Evoked] Potentials in Children With and Without Otitis Media. Texas Journal of Audiology and Speech Pathology 1999:10

36 Koravand A, Jutras B, Lassonde M. Cortical auditory evoked potentials in children with a hearing loss: a pilot study. Int J Pediatr 2012;2012:250254

37 Duncan CC, Barry RJ, Connolly JF, et al. Event-related potentials in clinical research: guidelines for eliciting, recording, and quantifying mismatch negativity, P300, and N400. Clin Neurophysiol 2009;120(11):1883-1908

38 Ors M, Lindgren M, Blennow G, Nettelbladt U, Sahlen B, Rosen I. Auditory eventrelated brain potentials in children with specific language impairment. Eur J Paediatr Neurol 2002;6(01):47-62 